\title{
ENHANCING LANGUAGE AND CROSS-CULTURAL COMPETENCE THROUGH TELECOLLABORATION
}

\author{
Ricardo Casañ-Pitarch ${ }^{1}$ (Corresponding author), \\ Miguel Ángel Candel-Mora ${ }^{2}$, Maria Luisa Carrió-Pastor ${ }^{3}$, \\ Olga Demydenko ${ }^{4}$, Iana Tikan ${ }^{5}$ \\ ${ }^{1,2,3}$ Universitat Politècnica de València, Spain, \\ ${ }^{4,5}$ Igor Sikorsky Kyiv Polytechnic Institute, Ukraine \\ ricapi@upv.es
}

\begin{abstract}
This paper presents an experiment which focused on determining if a telecollaborative project work would help enhance students' foreign language skills and cross-cultural competence. Students from Igor Sikorsky Kyiv Polytechnic Institute and the Polytechnic University of Valencia worked together during the fall term in 2020, in which 56 Ukrainian and Spanish students were engaged in a telecollaborative programme - 32 were master degree students at Igor Sikorsky Kyiv Polytechnic Institute, whereas the remaining 24 were bachelor engineering students at Polytechnic University of Valencia. Our students were engaged in a project work which consisted in the creation of a blog on the topic 'Sustainable Development Today'. The tools used in this project were mostly Google applications such as Classroom, Hangouts, Blogger, Drive, and Docs. In order to measure their progress, students took pre-tests before the project started and a post-test after its completion. These tests focused on assessing learners' language competence in English and also their cross-cultural competence. The language test used was designed by Cambridge University Press, whereas the cross-cultural test had been created by the Organizational Behavior Group (Piasentin, 2012). The latter focused on learners' willingness to engage, cognitive flexibility and openness, emotional regulation, tolerance of uncertainty, self-efficacy, and ethnocultural empathy. As expected, the students who participated in this virtual exchange programme enhanced their competence on both foreign language cross-cultural competences by taking an active part in the telecollaborative project work.
\end{abstract}

Keywords: language; cross-cultural competence; telecollaboration; project work.

\section{Introduction}

The development of language seems to have close bounds with the development of cross-cultural competence and vice-versa. Culture is expressed with language, and language is the tool by which any culture is represented. Thus, it seems inevitable that students of a foreign language need to develop their cross-cultural competence in order to fulfil their learning process. The one and the other are inseparable parts of the same puzzle, and none of them can exist without the other.

Researchers such as Lawton (1975), Tang (1999) or Tomalin (2008) have previously suggested that languages are necessary to show and describe any reality; and realities involve cultural knowledge, behaviour, and skills. If there is no culture to represent, the language would neither have any reason to exist. Byram (1991) introduced a model of foreign language teaching which included the learners' need for crosscultural development. Cross-cultural competence includes elements such as the expression of politeness, communicating behaviours, values, expectations, and perspectives. Foreign language learners need to absorb the cultural differences from the target language, and become aware of them in the practice. Rew et al. (2003, p.250) stated that "when individuals are conscious that people are different from one another, partly because of their cultural backgrounds, they are culturally aware"; and consequently, they can understand the other parts better and communicate more effectively.

Cross-cultural competence enables students to interact both effectively and in a way that is acceptable to others when they are working in a group whose members have different cultural backgrounds, where 'cultural' may denote all manner of features, including values and beliefs, their national, regional and local customs and, in particular, attitudes and practices that affect the way they work (Sadler \& Dooly, 2016). Similarly, the concept of cross-cultural competence, as stated by UNESCO, refers to having adequate relevant knowledge about particular cultures, as well as general knowledge about the sort of issues arising when members of different cultures interact, holding receptive attitudes that encourage establishing and maintaining contact with others, as well as having the skills required to draw upon both knowledge and attitudes when interacting with others from different cultures (Unesco, 2013). 
Considering these views, it seems that students could simultaneously enhance both their language skills and their communicative competence if they worked in a multi-cultural context. Unfortunately, in recent times, the mobility of students (or other individuals) has been quite limited. Programmes such as Erasmus have given rise to international exchanges of students from different countries. With these mobility programmes, students can learn a language immersed around the culture, resulting in real communication in a context with a foreign language and culture. Being these international exchanges the optimum solution to the development of both language and cultures, other alternatives such as telecollaboration have also risen in the last decades, and they imply new opportunities for language learners.

In the present age, learning and technology seem to go hand in hand, and as result teaching has become more dynamic, flexible, personalised and facilitates more effective learning processes. The development of communication technologies has also opened new resources and opportunities as well as new challenges for educators. In this sense, telecollaboration in foreign language learning has become a promising educational tool for students and teachers from different countries working and learning together online.

Telecollaboration is a hyponym of virtual exchange, and it consists in the use of technology to connect geographically distant students and teachers to have virtual encounters and work on lessons and activities (Sadler \& Dooly, 2016). By connecting teachers and students in different countries through interactive online tools (video conferencing, chat, forum, and blogs), telecollaboration provides an engaging environment for learning and practising foreign language skills, and for developing their cross-cultural competence through a project-based approach. Thereby, this research work focuses on the impact of a telecollaborative project work, not only on learning foreign language by students of different cultural background, but also on how it can help students enhance their cross-cultural competence in a virtual environment.

In words of O'Dowd (2018), telecollaboration is a form a virtual exchange, which follows similar rules as a physical one. Some authors have previously reported some benefits such as promoting international encounters and active participation while the use of a common language is a must, and in these cases the language could be different to the speakers' mother tongue (Bueno-Alastuey, 2013). Besides, students are normally engaged in exercises which require continuous meaning negotiation, an action that it is highly recommended within the foreign language classroom (Ellis, 2003).

Through project-based and task-based approaches, teachers facilitate students working immersed in concrete situations with specific tools, with which they must communicate with each other, negotiating the meaning of their own language to achieve specific objectives. Furthermore, project work allows the students to develop their communicative competence while working on tasks related to their degree and the professions derived from it. On the other hand, the use of ICT in this type of international projects is a fundamental aspect to be able to remotely connect students from different institutions, just as it happens in real-life professional contexts (Coll, Mauri, Onrubia, 2006). Today, education must integrate learning both in the real world and through virtual spaces. This integration of ICT in the classroom means that students can communicate and collaborate in the development of tasks without geographical barriers (Trujillo, 2005). This possibility implies that the student must also learn to deal with other individuals and work with international groups, and therefore, the development of certain cross-cultural competences is a requirement (Chambers, Conacher and Littlemore, 2004; Larrea Espinar, Raigón Rodríguez \& Gómez Parra, 2012).

In the field of telecollaboration, Guth and Helm (2010) explained that the development of cross-cultural competence is directly connected to language learning, "in language learning contexts, telecollaboration is generally understood to be Internet-based cross-cultural exchange between people of different cultural/national backgrounds, set up in an institutional context with the aim of developing both language skills and cross-cultural communicative competence through structured tasks" (p.14). Following this idea, Cunningham (2019) showed a review of the state-of-the-art regarding telecollaboration in the field of language learning and its connection with the development of learners' cross-cultural competence, from the initial studies in cultural exchange to the most recent in teaching of languages distinguishing three main approaches: telecollaboration for intercultural learning, telecollaboration for language learning, and telecollaboration for content learning, while highlighting the lack of studies in the approach aimed at teaching content combined with languages. Among the possibilities of virtual environments for language teaching, there is a wide range such as computer-mediated communication, eTandem, tele-tandem, online cultural exchange, virtual exchange, network-based language teaching, tele-collaboration (Lewis and O'Dowd, 2016), under the most recently denominated virtual exchange (O'Dowd, 2018; Cunningham, 2019).

This variety of approaches has led some authors to define the concept of telecollaboration; among other researchers, Belz (2003) defined it as follows: "telecollaboration involves the use of Internet communication tools by internationally dispersed students of language in institutionalized settings in order to promote the development of (a) foreign language (FL) linguistic competence and (b) intercultural competence" (68). 
Later on, this definition was completed by adding the 'remote access' component, and including newer devices. Finally, from the perspective of language teaching and intercultural competence, the role of the teacher as a facilitator of the process of virtual exchange is included as an integrated methodology in the context of the educational programme "with the aim of developing learners' foreign language skills, digital literacies, and intercultural competence" (O'Dowd and O'Rourke, 2019, p.1). Likewise, Dooly (2017) stated that telecollaboration studies are more abundant in fields related to language teaching and learning such as L1, L2, foreign, ESL, or ESP, as well as in the development of intercultural competences (170). It shall be noticed though that public and private initiatives are increasingly emerging and they promote the use of virtual exchange platforms in other disciplines such as the Collaborative Online International Learning (COIL) of the SUNY university network, which connects courses with similar content in different countries, or initiatives as X-Culture, aimed at students of business management and administration programmes that allow them to work in international virtual teams (O'Dowd and O'Rourke, 2019, p.1).

Regarding research in telecollaboration, it shall be acknowledged that projects vary a great deal from one to another. Virtual exchange projects are developed in various dimensions, and with different profiles of participants and objectives, the literature reviewed identifies various research perspectives that range from studying the effects of technology and the platform on which the experience has been developed (Helm and Guth, 2010; Lewis and O'Dowd, 2016; Chapelle and Sauro, 2017; Dooly, 2017; Dooly and Sadler, 2013; Guth, \& Thomas, 2010), the challenges and difficulties of telecollaboration for language teaching (PérezCañado, 2012; Dooly, 2008; Guth, \& Helm, 2012; Helm \& Guth, 2016; O'Dowd, 2017; Tudini, 2010), the exploitation of the social dimension (Belz, 2002), the development of intercultural competence (Belz, 2003; Çiftçi, and Savaş, 2018), to the study of the degree of digital literacy acquired by the participants (Helm, 2014; Spiers and Bartlett, 2012). However, a more detailed study of the literature reveals that in most cases it is difficult to identify a single research focus; they can be studied both from the professor's point of view (O'Dowd, 2017; Dooly and Sadler, 2013) or from the student's point of view (Lee and McLoughlin, 2007; Guth, and Helm, 2012; Canto and Jauregui, 2017). What undoubtedly seems to be the common thread of research in virtual environments is the versatility of this methodology and the possibility of using it from multiple perspectives during the design, development and completion phases of the experience of collaboration. Thus, White (2017) highlights that participation in this type of virtual exchanges involve different challenges during its development that entails that the participant learns and adapts to them during their performance in the virtual community.

At last, it should also be acknowledged that the benefits of telecollaboration are multiple according to other researchers. Bueno-Alastuey (2011) and Guth and Marini-Maio (2010) explained that telecollaboration helps enhance lexicon, grammar and pronunciation. Similarly, Tian and Wang (2010) and Polisca (2011) suggested that telecollaboration helps enhance language fluency and students would gain confidence in speaking with other colleagues using a foreign language. In the field of foreign languages, Jauregi and Bañados (2008) also suggested that group working in virtual environments could raise learners' motivation, whereas Cunningham and Vyatkina (2012) appointed that digital competences are enhanced in telecollaboration projects. At last, Helm and Guth (2010) also explained that the intercultural component can also be enhanced by students who participate in this type of virtual exchange.

Within this context, the objective of this research is to assess our participants' progress on foreign language skills and see how they developed their cross-cultural competence through the completion of a telecollaborative project work. Our hypothesis is that students will enhance their foreign language skills and cross-cultural competence through a telecollaborative project work. This project work consisted in the creation of a blog dealing with environmental issues (Sustainable Development). Students worked collaboratively in groups and their product had to be presented in class at the end of the term. The participants within this research were students at Universitat Politècnica de València (UPV) and Igor Sikorsky Kyiv Polytechnic Institute (KPI).

\section{Methods}

\section{Research Design}

This research focuses on helping students from two institutions to enhance foreign language skills (English) and develop their cross-cultural competence through a telecollaborative project work. Our students participated in a telecollaborative project work between February and May 2020. The method of this research is quantitative. The description of the participants, materials used, and the procedure to implement this teaching proposal are explained in detail below. 


\section{Participants}

The number of participants in this experiment was 56. Among these participants, 32 students were students of a Master degree in Translation at KPI; the other 24 were industrial engineering students at UPV. All the students did the pre-test, participated and completed the project, and finally did the post-test. Our participants were divided in groups of 4 and 5 students, the number of groups was 12, and the nationalities were mixed (Spanish and Ukrainian). The students confirmed that they had never participated in a telecollaborative project work with foreign students. Our participants also agreed that the results from this experiment could be treated anonymously.

\section{Instruments and Procedure}

In order to measure learners' progress, two tests were used. On the one hand, L2 learners' progress was assessed with the test entitled 'English Unlimited Placement Test' (Cambridge University Press, 2010). This test contains 120 multiple choice questions and it covers the language level from A2 to $\mathrm{C} 1$. In order not to repeat the questions, it was decided that each test would contain 60 questions. The pre-test would introduce the odd numbers (i.e.:1, 3, 5), and the post-test would use the even numbers (i.e.: 2, 4, 6).

On the other hand, the survey introduced by Piasentin (2012) was used to assess learners' progress on their cross-cultural competence. This survey used a 5-item Likert scale and the questions represented six blocks. These blocks are shown in Figure 1.

\begin{tabular}{|l|l|}
\hline Block 1 & Willingness to Engage \\
\hline Block 2 & Cognitive Flexibility \& Openness \\
\hline Block 3 & Emotional Regulation \\
\hline Block 4 & Tolerance of Uncertainty \\
\hline Block 5 & Self-Efficacy \\
\hline Block 6 & Ethnocultural Empathy \\
\hline
\end{tabular}

Figure 1. Assessing Cross-Cultural Competence.

Students took the pre-tests during the first week of classes and the post-tests after they had completed the telecollaborative project-work. The purpose of this project-work was to engage students in the creation of a blog on the topic 'Sustainable Development'. Students were expected to spend approximately 15 hours working in the elaboration of the project. The completion of the project entailed 3 stages:

- Stage 1: group formation and instructing students on how to work in this project and use some Google Applications (Blogger, Classroom, Drive, Hangouts). In addition, students also receive specific language training based on the usual vocabulary and expressions related to the topic.

- Stage 2: students had to meet in at least 3 occasions via video conference and agree on the organisation of a blog and create it. The blog had to contain one entry for each member of the group, half of them should be written and the other half oral. Meetings had to be recorded in videos, and a report on the most important decision taken (minutes) should be written, including an agenda of their meetings. These documents had to be uploaded to their group's Google Drive folder, which should be shared only among the group members and the instructors.

- Stage 3: after the completion of their blogs, the last stage was addressed to the assessment of their work. Firstly, groups had to discuss and assess another group's blog and give them some feedback in a subsequent virtual meeting; this feedback was given reciprocally. After receiving feedback from the other group, they had one week to sort out possible problems and improve their blogs. Finally, students showed their blogs to the instructors in an online meeting, and they had to explain its contents. Consequently, they were assessed by the instructors

Regarding the assessment of this task, four elements were considered: blogs' peer-review (2 points), compliance of tasks such as attending to meeting and writing reports ( 3 points), teachers' blog assessment ( 3 points), and final group oral presentation ( 2 points). The peer review consisted in giving feedback to another group on how they could improve their work and grade their blog in terms of content (0.4), originality (0.4), feasibility (0.4), language (0.4), and quality (0.4). Secondly, the compliance of tasks consisted in uploading one video for each of the 5 meetings, their reports and minutes. Thirdly, teachers assess the students' blogs using the same elements assessed by the students. At last, students presented their work in class, explaining the content of their written production and videos. In this case, the assessment focuses on the students' communication skills. 


\section{Results}

This section introduces the results obtained on the learners' progress of language and cross-cultural skills. They are presented individually. To start with, our results show that students from both institutions enhanced their language skills. On the one hand, KPI students' level was higher than UPV students, but their progress was lower. In this sense, their initial level was 8.35 out of 10 , and they raised their score to 8.85 after this project. This implies a per cent variation of 5.99\%. On the other hand, students from UPV initially scored 7.22 at the pre-test, and their language level improved to 7.77. The per cent variation of their progress was $7.62 \%$. In addition, results also show that the difference between KPI and UPV students was $15.65 \%$ at the pre-test, being the Ukrainian students higher. In the post-test, this difference was shortened to $13.90 \%$. These results imply that both groups of students enhanced their language skills during the completion of this project. The general progress of both groups was from 7.87 to 8.39 ; this rise means $6.61 \%$ of per cent variation. Table 1 and Figure 2 show the results obtained.

\begin{tabular}{|l|l|l|l|l|l|}
\hline & Particip. & Pre & Post & Dif. & V\% \\
\hline KPI & 32 & 8.35 & 8.85 & 0.50 & 5.99 \\
\hline UPV & 24 & 7.22 & 7.77 & 0.55 & 7.62 \\
\hline General & 56 & 7.87 & 8.39 & 0.52 & 6.61 \\
\hline \multicolumn{2}{|c|}{ V\% } & 15.65 & 13.90 & & \\
\hline
\end{tabular}

Table 1. Students' Language Progress

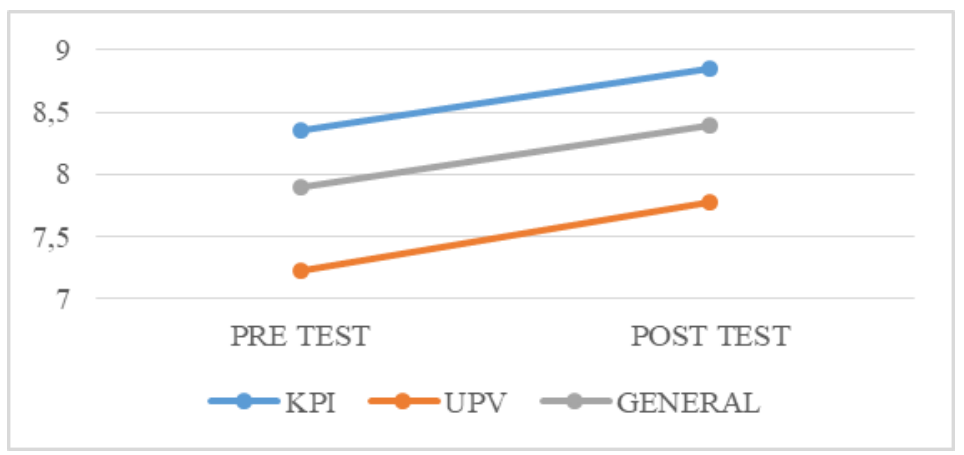

Figure 2. Students' Language Progress

In addition to our learners' language progress, the development of their cross-cultural skills was also assessed with the test designed by Piasentin (2012). As previously explained, this test contains different blocks, and all the students did not progress in the same way. However, it shall be noticed that their general progress, considering the mean of the six blocks, was $9.67 \%$. This could be used as a reference.

Tables 2, 3 and 4 and Figure 3 shows the results obtained regarding learners' cross-culture development. In general terms, the students' progress on cross-cultural competence was $9.67 \%$; and the progress from students from both institutions was similar (KPI: 9.71\% - UPV: 9.60\%). In addition, our participants progressed in all the fields in the test; although there were some differences between the two groups.

Results suggest that students progressed the most in blocks 1, 4 and 6, in which their progress was higher than 10\%. In this sense, the progress in block 6, 'Ethnocultural Empathy', was clearly noticeable and superior to the other blocks $(16.00 \%)$. On the contrary, students scored the lowed in the 'Cognitive Flexibility \& Openness' block, in which the general progress was $3.27 \%$.

If the two groups are compared, it can be observed that students' progress in blocks 1, 3, 4, and 5 was similar; the difference between the two groups was inferior to 1 . However, some differences were detected in blocks 4 and 6. In block 4, 'Tolerance of Uncertainty', the Spanish students progressed more than the Ukrainians. The opposite happened in block 6, 'Ethnocultural Empathy', the KPI students showed a considerably higher progress within this field.

\begin{tabular}{|l|l|l|l|l|}
\hline General & Pre-Test & Post-Test & Dif. & V\% \\
\hline Block 1 & 3.91 & 4.34 & 0.43 & 11.00 \\
\hline Block 2 & 3.98 & 4.11 & 0.13 & 3.27 \\
\hline Block 3 & 3.47 & 3.82 & 0.35 & 10.09 \\
\hline Block 4 & 3.5 & 3.81 & 0.31 & 8.86 \\
\hline Block 5 & 3.77 & 4.13 & 0.35 & 9.55 \\
\hline Block 6 & 3.5 & 4.06 & 0.56 & 16.00 \\
\hline TOTAL & 3.69 & 4.05 & 0.36 & $\mathbf{9 . 6 7}$ \\
\hline \multicolumn{6}{|l}{ Table 2. Students' Cross-culture Progress } \\
\hline
\end{tabular}




\begin{tabular}{|l|l|l|l|l|}
\hline KPI & Pre-Test & Post-Test & Dif. & V\% \\
\hline Block 1 & 3.99 & 4.42 & 0.43 & 10.78 \\
\hline Block 2 & 4.01 & 4.13 & 0.12 & 2.99 \\
\hline Block 3 & 3.46 & 3.81 & 0.35 & 10.12 \\
\hline Block 4 & 3.52 & 3.77 & 0.25 & 7.10 \\
\hline Block 5 & 3.8 & 4.16 & 0.36 & 9.47 \\
\hline Block 6 & 3.46 & 4.11 & 0.65 & 18.79 \\
\hline TOTAL & 3.71 & 4.07 & 0.36 & $\mathbf{9 . 7 1}$ \\
\hline \multicolumn{4}{|l}{ Table 3. KPI Students' Cross-culture Progress } \\
\hline
\end{tabular}

\begin{tabular}{|l|l|l|l|l|}
\hline UPV & Pre-Test & Post-Test & Dif. & V\% \\
\hline Block 1 & 3.81 & 4.23 & 0.42 & 11.02 \\
\hline Block 2 & 3.94 & 4.08 & 0.14 & 3.55 \\
\hline Block 3 & 3.49 & 3.83 & 0.34 & 9.74 \\
\hline Block 4 & 3.48 & 3.87 & 0.39 & 11.21 \\
\hline Block 5 & 3.73 & 4.09 & 0.36 & 9.65 \\
\hline Block 6 & 3.53 & 3.99 & 0.46 & 13.03 \\
\hline TOTAL & 3.66 & $\mathbf{4 . 0 2}$ & 0.35 & $\mathbf{9 . 6 0}$ \\
\hline \multicolumn{6}{|l}{ Table 4. UPV Students' Cross-culture Progress } \\
\hline
\end{tabular}

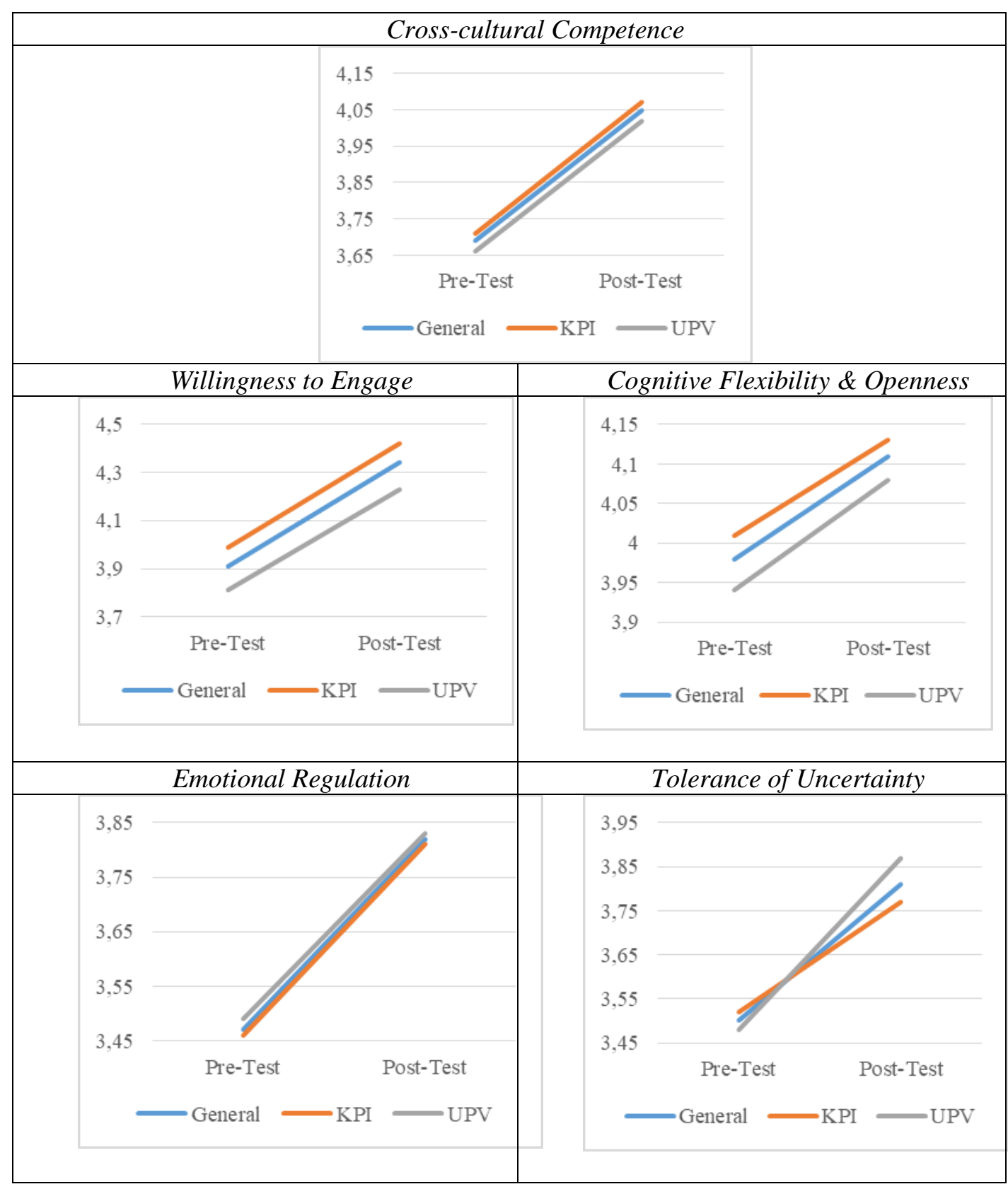




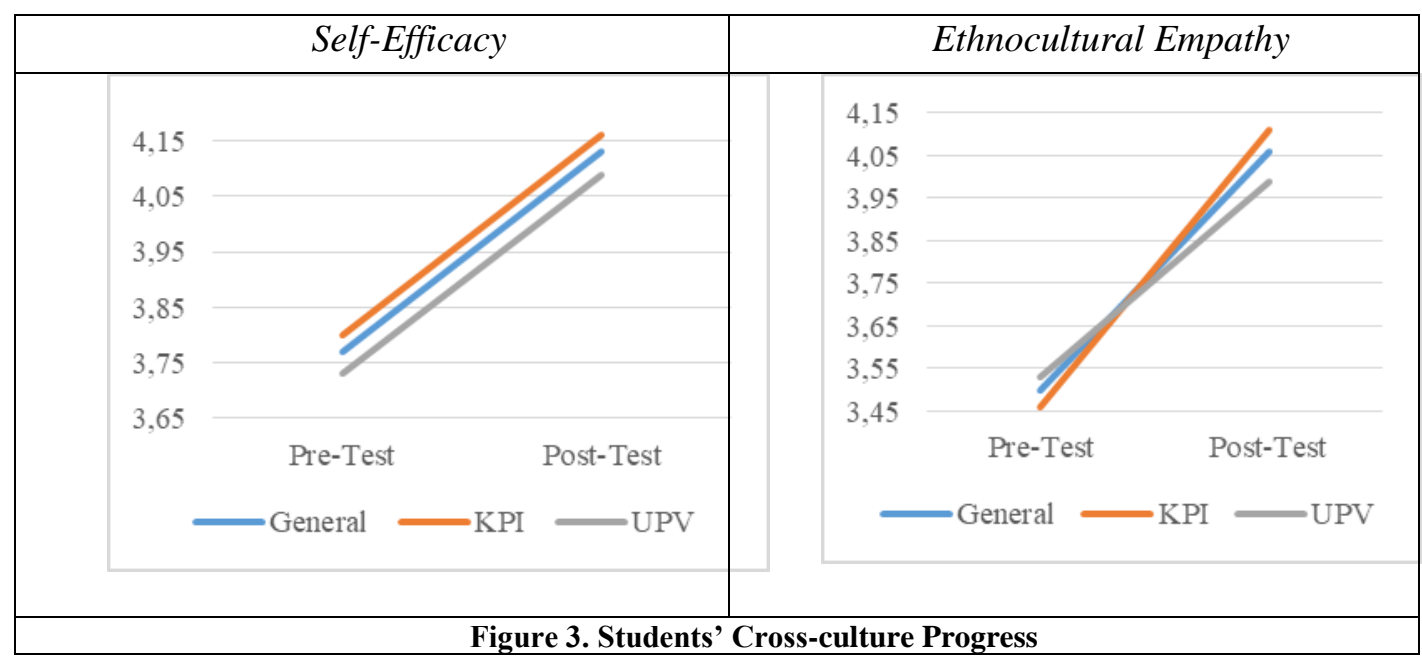

In general, results in this section have shown that participants progressed and enhanced both their language skills and cross-cultural competence. As stated in our initial hypothesis, these were the results that were expected to be found, as suggested in previous studies. The reasons for this progress should be discussed in the following section, considering some minor differences among the two groups that have been identified.

\section{Discussion}

As shown in the results, it seems that telecollaborative project work in a multinational context is beneficial for students from a linguistic and cross-cultural perspective. On the one hand, students enhanced their language skills as shown in the tests' results. The opportunities that they found to practice language skills in a real context made that the theoretical content that the participants had studied in class could be implemented in a real context. Previous authors had reported that students would enhance their lexicon, grammar, pronunciation, fluency, and students would increase their motivation and confidence to speak in public using a foreign language (Bueno-Alastuey, 2011; Guth \& Marini-Maio, 2010; Jauregi and Bañados, 2008; Polisca, 2011; Tian \& Wang, 2010).

For the interest of this paper, our aim was to check if students would enhance their language skills together with their cross-cultural competence, and according to our results, students achieved these objectives during the three months of the experience. Previously, Helm and Guth (2010) had already reported that the cross-cultural component would also be enhanced by those students participating in a virtual exchange with students whose mother tongue was different to theirs. Thus, by communicating with the target language, as a lingua franca, would raise the opportunities to interact at the same time they learned how to deal with people from different backgrounds, behaviours, or values.

Results have shown that the students enhanced their cross-cultural competence by near $10 \%$, which we believe is reasonable given the time and the scenario. Probably, the progress would have been higher in a more immersive scenario, such as living in a foreign country where they would spend all their time immersed in the target language and culture. Yet, it seems that this online opportunity was beneficial for students from both universities.

We also believe that this first experience among multinational students in a project work helped them break with some initial prejudices and gain confidence to work in this type of virtual environments. These facts seem to be noticeable in their progress on their tolerance of uncertainty and emotional regulations. Students initially seem to be anxious because of the idea of having to work with people from another country in a virtual environment, and the start of the project was slow. However, as the time passed our students began to feel more confident and their communication was more fluent and also effective. Thus, the fact of breaking this initial cross-cultural barrier and realise that both parts were willing to engage in the same project work was fundamental. This was possible because participants from both institutions shared the same common objective, and their academic marks depended on its completion. This also was noticeable in our students' self-efficacy, once they felt secure of their possibilities and get to know the members of their group, their work was increasingly more efficient.

Results also showed that students specially improved their capacity to understand the feelings and emotions of people from a different country; known in the test as ethnocultural empathy. As suggested, we 
believe that participating in this pioneering experience changed their perspective towards other realities, and they broke with certain cultural prejudices.

For some reason, students' progress towards cognitive flexibility and openness was inferior to the rest of skills in the test. Their ability to switch between thinking should be further improved according to the results obtained. A possibility to justify this fact is that students worked in groups of four, but at least another member from the group had the same nationality. Therefore, even though all the students completed the project work properly, we can intuit that there was more contact with the students with the same nationality. Therefore, communication was possibly not all the time with people sharing the same language and culture. A possible solution to this problem would be to create groups with students from different nationalities and speaking different languages, none of the members should have a language in common. This would probably give rise to a better immersion with the multi-cultural community.

Some limitations in the research shall also be acknowledged. To start with, we think that the adding new institutions from other countries could lead to enhance the present results. If students avoided contact with students from the same institution and speaking the same language, their degree of immersion in a multilingual and multi-cultural context would be higher. Secondly, implementing this project during a longer period would also be beneficial; unfortunately, the two institutions had different academic calendars and this made that the length of this project was shorter. Despite these limitations, our students were satisfied with the implementation of these projects according to the results in the final satisfaction survey carried out at the end of the semester.

\section{Conclusions}

According to the results obtained in our experiment, it seems that students have enhanced both their language and cross-cultural competence. This telecollaborative experience has been possible thanks to the present technology. As previously stated, the development of technology in the $21^{\text {st }}$ century has helped to hold encounters among international teams and work together. As results have shown, students have had a reasonable amount of time to practice their language skills with people from a different country and work together in a project work, in which the understanding of people with different cultural backgrounds has been fundamental. The objective of this research was to assess learners' language and cross-cultural progress, and the results seem to have confirmed our hypothesis.

Our hypothesis had been based on previous research from other authors, who had suggested that students could enhance their foreign language skills and cross-cultural competence through a telecollaborative project work. In this case, our participants created a blog on the topic of sustainable development. They used some Google tools such as classroom, drive, or hangouts, among others; and met regularly in order to arrange the organisation and content of the blog. This work in group seems to have helped learners enhance their language skills in a specific context as suggested in our theoretical framework

Furthermore, during the implementation of this project, it was also expected that our students would develop their autonomy, group work skills, critical thinking, and related to business and corporate area such as making presentations, negotiating, attending and participating in meetings, or persuading others. Besides, it is also unquestionable that the fact that this project work was carried out online with different digital tools, learners also learned how to use them; consequently, they developed their digital skills. Not only knowing how to use them, but creating new content and communicating it to the other colleagues and their instructors. Although the development of these skills has not been confirmed in this paper, our further research could go on this line.

In sum, telecollaborative project work seems to be suitable to foreign language learners since the opportunities to interact and practise with other students whose mother tongue is different increase considerably, and consequently, they will be also enhancing their cross-cultural competence without moving geographically.

\section{Acknowledgements}

We would like to show our gratitude to all the students from UPV and KPI who participated in this project during the academic year 2019/2020.

This work is one of the results of the teaching innovation project "Development of English language communication skills for engineering students through virtual collaboration in international projects" funded by the Vice-rectorate of Studies and Educational Quality of the Universitat Politècnica de València, Spain: Call for Learning + Teaching 2019. Projects of Innovation and Educational Improvement. 


\section{References:}

Belz, J. A. (2002). Social dimensions of telecollaborative foreign language study. Language Learning \& Technology, 6(1), 60-81. http://dx.doi.org/10125/25143

Belz, J. A. (2003). Linguistic perspectives on the development of intercultural competence in telecollaboration. Language Learning \& Technology, 7(2), 68-99. http://dx.doi.org/10125/25201

Bueno Alastuey, M.C. (2011). Perceived benefits and drawbacks of synchronous voice-based computer-mediated communication in the foreign language classroom. Computer Assisted Language Learning, 24(5), 419-432. https://doi.org/10.1080/09588221.2011.574639

Bueno-Alastuey, M.C. (2013). Interactional feedback in synchronous voice-based computer mediated communication: Effect of dyad. System, 41(3), 543-559. https://doi.org/10.1016/j.system.2013.05.005

Byram, M. (1991). Integrated Model. Mediating languages and cultures: Towards an intercultural theory of foreign language education. In Buttjes, D., \& Byram, M. (Eds.), Mediating languages and cultures: Towards an intercultural theory of foreign language education (pp. 17-31). Multilingual Matters.

Cambridge University Press (2010). English Unlimited Placement Test. Retrieved from https://www.cambridge.es/content/download/1584/10218/EU_PlacementTest_WrittenTest.pdf [Accessed 02 Octiber 2020].

Canto, S., \& Jauregi, K. (2017). Language learning effects through the integration of synchronous online communication: The case of video communication and Second Life. Language Learning in Higher Education, 7(1), 21-54. http://dx.doi.org/10.1515/cercles-2017-0004

Chambers, A., Conacher, J. E., \&Littlemore, J. (2004). ICT and language learning. A\&C Black.

Chapelle, C. A., \& Sauro, S. (eds.) (2017). The handbook of technology and second language teaching and learning. Wiley Blackwell.

Coll, C; Mauri, T; \& Onrubia, J; (2006). Análisis \& resolución de casos-problema mediante el aprendizaje colaborativo. Universities and Knowledge Society Journal, 3(1) 29-41. http://dx.doi.org/10.7238/rusc.v3i2.285

Cunningham, D. J. (2019). Telecollaboration for content and language learning: A Genre-based approach. Language Learning \& Technology, 23(3), 161-177. http://hdl.handle.net/10125/44701

Cunningham, D. J., \& Vyatkina, N. (2012). Telecollaboration for professional purposes: Towards developing a formal register in the foreign language classroom. Canadian modern language review, 68(4), 422-450. https://doi.org/10.3138/cmlr.1279

Çiftçi, E., \& Savaş, P. (2018). The role of telecollaboration in language and intercultural learning: A synthesis of studies published between 2010 and 2015. ReCALL, 30(3), 278-298. https://doi.org/10.1017/S0958344017000313

Dooly, M. (2008). Telecollaborative language learning. A guidebook to moderating intercultural collaboration online. Peter Lang.

Dooly, M. (2017). Telecollaboration. In Chapelle, C. A., \& Sauro, S. (eds.), The handbook of technology and second language teaching and learning (pp. 169-183). Wiley Blackwell.

Dooly, M., \& Sadler, R. (2013). Filling in the gaps: Linking theory and practice through telecollaboration in teacher education. ReCALL, 25(1), 4-29. https://doi.org/10.1017/S0958344012000237

Ellis, R. (2003). Task based language learning and teaching. Oxford University Press.

Guth, S., \& Helm, F. (2010). Telecollaboration 2.0: Languages, Literacies and Intercultural Learning in the 21st Century. Peter Lang.

Guth, S. \& Helm, F. (2012) Developing multiliteracies in ELT through telecollaboration, ELT Journal, 66(1), $42-51$. https://doi.org/10.1093/elt/ccr027

Guth, S., \& Marini-Maio, N. (2010). Close encounters of a new kind: The use of Skype and Wiki in telecollaboration. In S. Guth \& F. Helm (eds.), Telecollaboration 2.0 (pp. 413-427). Peter Lang.

Guth, S. \& Thomas, M. (2010) Telecollaboration with Web 2.0 Tools. In F. Helm \& S. Guth (eds.), Telecollaboration 2.0: Languages, Literacies and Intercultural Learning in the 21st Century (pp. 39-68). Peter Lang.

Helm, F. (2014). Developing digital literacies through virtual exchange. Elearning Papers, 38, 1-10. Retrieved from: http://www.academia.edu/download/37764333/From-field_38_4_1.pdf

Helm, F. \& Guth, S. (2010). The multifarious goals of telecollaboration 2.0: Theoretical and practical implications. In F. Helm and S. Guth (eds.), Telecollaboration 2.0: Languages, Literacies and Intercultural Learning in the 21st Century (pp. 69-106). Peter Lang.

Helm, F. \& Guth, S. (2016). Telecollaboration and language learning. In F. Farr \& L. Murray (eds.), The Routledge Handbook of Language Learning and Technology, chapter 17. Routledge.

Jauregi, K., \& Bañados, E. (2008). Virtual interaction through video-web communication: A step towards enriching and internationalizing learning programs. ReCALL, 20(2), 183-207. https://doi.org/10.1017/S0958344008000529

Larrea Espinar, A. M., Raigón Rodríguez, A. R., \& Gómez Parra, M. E. (2012). ICT for intercultural competence development. PixelBit: Revista de Medios \& Educación, 40, 115-124. Retrieved from: https://recyt.fecyt.es/index.php/pixel/article/view/61439

Lawton, D. (1975). Class, culture and the curriculum. Routledge.

Lee, M. J., \& McLoughlin, C. (2007). Teaching and learning in the Web 2.0 era: Empowering students through learner-generated content. International journal of instructional technology and distance learning,4(10), 21-34. Retrieved from: http://www.itdl.org/Journal/Oct_07/article02.htm

Lewis, T. \& O'Dowd, R. (2016). Online Intercultural Exchange and Foreign Language Learning: a Systematic Review. In R. O'Dowd \& T. Lewis (eds.), Online Intercultural Exchange: Policy, Pedagogy, Practice (pp. 21-66). Routledge.

O’Dowd, R. (2017). Virtual Exchange and internationalising the classroom. Training Language and Culture, 1(4), 8-24. https://doi.org/10.29366/2017tlc.1.4.1

O'Dowd, R. (2018). From telecollaboration to virtual exchange: State-of-the-art and the role of UNICollaboration in moving forward. Research-publishing.net, Journal of Virtual Exchange, 1(1), 1-23. https://doi.org/10.14705/rpnet.2018.jve.1

O’Dowd, R., \& O'Rourke, B. (2019). New developments in virtual exchange for foreign language education, Language Learning \& Technology, 23(3), 1-7. http://hdl.handle.net/10125/44690

Pérez-Cañado, M. L. (ed.). (2012). Competency-based language teaching in higher education. Springer Science \& Business Media.

Piasentin, K. (2012). Assessing Cross-Cultural Competence Implications for Selection and Training in the Canadian Forces. Organizational Behaviour Group Socio-Cognitive Systems Section. 
Polisca, P. (2011). Language learning and the raising of cultural awareness through Internet telephony: A case study. The Language Learning Journal, 39(3), 329-343. https://doi.org/10.1080/09571736.2010.538072

Rew, L., Becker, H., Cookston, J., Khosropour, S., \& Martinez, S. (2003). Measuring cultural awareness in nursing students. Journal of Nursing Education, 42(6), 249-257. Retrieved from: https://pubmed.ncbi.nlm.nih.gov/12814215/

Sadler, R. \& Dooly, M. (2016). Twelve years of telecollaboration: What we have learnt. ELT Journal, 70 (4), $401-413$. https://doi.org/10.1093/elt/ccw041

Spires, H., \& Bartlett, M. (2012). Digital literacies and learning: Designing a path forward. NC: Friday Institute White Paper Series.

Tang, R. (1999). The place of culture in the foreign language classroom: A reflection. The Internet TESL Journal, 5(8), 1-2. Retrieved from: http://iteslj.org/Articles/Tang-Culture.html

Tian, J., \& Wang, Y. (2010). Taking language learning outside the classroom: Learners' perspectives of eTandem learning via Skype. Innovation in Language Learning and Teaching, 4(3), 181-197. https://doi.org/10.1080/17501229.2010.513443

Tomalin, B. (2008). Culture-the fifth language skill. Teaching English,48(1), 130-141. Retrieved from: https://www.teachingenglish.org.uk/article/culture-fifth-language-skill

Trujillo, F. (2005). En torno a la interculturalidad: reflexiones sobre cultura \& comunicación para la didáctica de la lengua. Porta Linguarum, 4(1), 23-39. Retrieved from: https://www.ugr.es/ portalin/articulos/PL_numero4/trujillo.pdf

Tudini, V. (2010). Online second language acquisition: Conversation analysis of online chat. Continuum.

UNESCO (2013). Intercultural competences: Conceptual and operational framework.

White, C. J. (2017). Distance Language Teaching with Technology. In C. A. Chapelle \& S. Sauro (eds.), The Handbook of Technology and Second Language Teaching and Learning (pp. 135-148). Wiley-Blackwell.

Received: October 16, 2020

Accepted: November 16, 2020 